\title{
UM CASO DE ALBINISMO EM TACHÃ (CHAUNA TORQUATA, OKEN) (AVES, ANSENIFORMES) OCORRIDO NA ESTAÇÃO ECOLÓGICA DO TAÍM, RIO GRANDE DO SUL, BRASIL
}

\author{
Luiz Alberto Veiga ${ }^{1}$ \\ Alfredo T. de Oliveira ${ }^{2}$
}

\begin{abstract}
ABSTR ACT. A CASI: OF AL BINISM IN SOUTHERN SCREAMER (CIAAUNA TORQUUATA, OKEN) (AVES, ANSINIFORMES) OCCIRRED AT THE ECOL.OSICAL. SIATION OF TAIM. RIO GRANDE DO SIL, BRAZII.. It is described herein a case study of albinism in Chauna torquata Oken. 1816 (Southern screamer) occurred at the Ecological Station of Taim. Rio Grande do Sul, Brazil. Sereamers are birds of marshes, wet grasslands and forest lagoons. The bill is short and curved, the head is small and slender and the neck rather short. The strong wings are armed with two large. sharp spurs on their forward edge. The feet and legs are fleshy, the lower half of the tibia is bare. and the three long front toes show just a trace of webhing between them. They are often seen walking in pairs on the floating masses of vegetation or in large groups for feeding. The albino specimen described herein was observed feeding in the midst of a group of almost fifty hirds. Their plumage was white hut their legs and bill were normally red pigmented, and also presented a light grey ring on its neck. It did not represent a case of total albinism, in which pigment should be totally absent.

KEY WORDS. Anseniformes, Anhimidae, Chatuna torquata, Southern sereamer, albinism
\end{abstract}

Variações hereditárias podem ser observadas entre membros de uma população selvagem mas os resultados são difíceis de serem relatados e discutidos, em conseqüência das dúvidas que geralmente se apresentam ao pesquisador. Estas variações de caráter genético requerem métodos muito especiais para realização de estimativas de freqüência de genes mutantes. Freqüentemente, portadores de tipos de mutação, como é o caso do albinismo descrito nesta comunicação, em virtude de suas próprias dificuldades, seja de visão ou de dissimulação no meio ambiente, não permanecem por muito tempo vivos, em condições selvagens (VEIGa \& PARDO 1990).

Levando em consideração o caráter recessivo do albinismo, um indivíduo albino pode ser cruzado com um normal, sem que gerem filhos albinos (W ALTER 1938). Contudo, os produtos de tal cruzamento podem gerar heterozigotos com possibilidade de produzirem portadores desta anomalia genética (HARRIS 1962; LERNER \& FITZPATRICK 1950; MAYS 1981; VEIGA \& PARDO 1990).

1) Setor de Ciências Biológicas, Universidade Federal do Paraná. Caixa Postal 19046, 81531-990 Curitiba. Paraná. Brasil.

2) Estação Ecológica do Taím. Rio Grande do Sul, Brasil. 
As aves se apresentam como o grupo mais expressivo entre os representantes da fauna da Estação Ecológica do Taím (SICK 1984; BELTON 1978, 1984; Silva \& CAYE 1992; VeIGA et al. 1995), no Rio Grande do Sul, com mais de 230 espécies representantes, dentro de um conjunto de milhões de aves. Considerando a afirmação de WALTER (1938), segundo a qual um em cada vinte mil indivíduos pode apresentar algum tipo de albinismo, é esperado que nesse Santuário Ecológico ocorra, vez por outra, algum portador desta anomalia.

A ocorrência de albinismo em aves é rara. Segundo SiCK (1984), foram observados alguns sabiás albinos (Turdus rufiventris Vieillot, 1818 e Platycichla flavipes Vieillot, 1818), na Floresta da Tijuca (Rio de Janeiro). VEIGA \& PARDO (1990) e VEIGA (dados não publicados) verificaram a existência de mais cinco exemplares de $T$. rufiventris portadores de albinismo, em Curitiba (Paraná).

A finalidade da presente publicação é a de relatar a ocorrência de um caso raro de albinismo em Chauna torquatı Oken, 1816 na Estação Ecológica do Taím (Rio Grande do Sul, Brasil).

\section{DESCRIC̣ÃO DA OCORRÊNCIA}

Numa de suas viagens de estudo à Estação Ecológica do Taím, em novembro de 1994, o autor senior foi informado por um dos fiscais do Instituto Brasileiro do Meio Ambiente (IBAMA), da existência de um indivíduo albino vivendo como participante de um dos vários grupos de Tachãs (Chauna torquata), que se espalham pelos banhados. Este grupo costumava alimentar-se numa região alagada, nos fundos da Lagoa Jacaré, lá para os lados do Albardão. A busca foi acertada para iniciar-se na manhã do dia seguinte, num barco de alumínio com motor de 20 HP. O exemplar albino foi localizado, com auxílio de binóculos, depois de quatro horas de intensiva procura na região adrede indicada, alimentando-se num baixio, juntamente com um bando de mais de 50 aves da mesma espécie. Foram tentadas várias aproximações e, em cada uma, feitas fotografias (Nikon F-301 com objetiva Sigma 70-300mm) e tomadas de cenas com filmadora de vídeo (Sharp JetZoom 12, modelo VL-L4100). A cada vez que o grupo de aves levantava vôo, em virtude das aproximações realizadas, o sub-grupo no qual o Tachã albino permanecia, durante a fuga, era seguido com binóculos, para ser feita nova aproximação. O espécime albino aqui descrito fazia parte de um grupo de cerca de 50 aves que se alimentava no banhado. Sua plumagem branca contrastava bastante com a cinza de seus companheiros. Este exemplar, apesar de apresentar as penas brancas, possuía pigmentação avermelhada nas pernas, bico e região ocular. No pescoço mostrava um anel levemente acinzentado contrastando com o cinza forte de seus companheiros normais. Não representa um caso de albinismo total, onde a pigmentação deveria estar totalmente ausente. É importante acrescentar que o indivíduo albino em estudo estava sendo bem aceito pelo grupo do qual fazia parte, não se notando qualquer atitude de rejeição contra o mesmo. A figura 1 mostra uma das cenas onde aparece o exemplar albino de Chauna torquata (Tachã) em companhia de um indivíduo normal. 


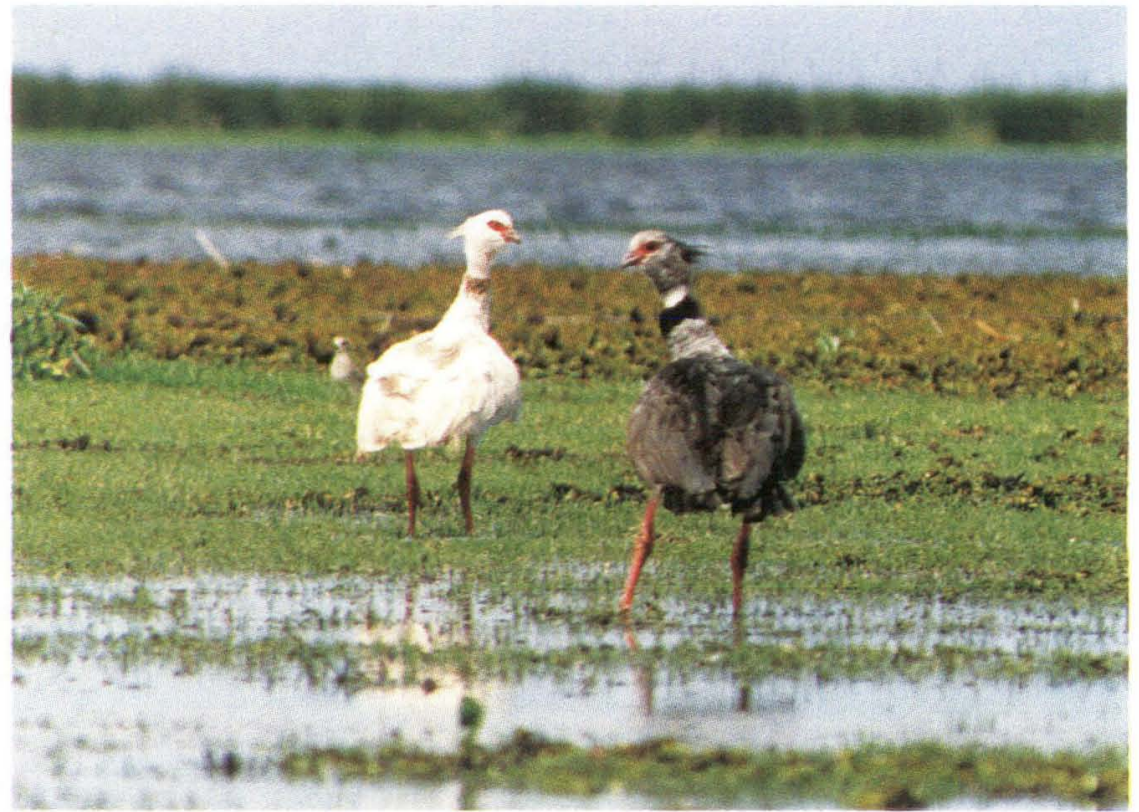

Fig. 1. Exemplar albino de Tachã (Chauna torquata, Oken 1816), localizado em novembro de 1994, nos banhados da Estação Ecológica do Taím. A fotografia do animal portador de albinismo, junto com um indivíduo normal, foi feita com uma câmera Nikon F-301, utilizando um filme "Kodak Gold plus" de 100 ASA.

\section{REFERÊNCIAS BIBLIOGRÁFICAS}

Belton, W. 1978. A List of Birds of Rio Grande do Sul, Iheringia, Sér. Zool., 52: $85-102$.

1984. Birds of Rio Grande do Sul, Brazil. I. Rheidae through Furnaridae. Bull. Am. Mus. Nat. Hist. 178: 369-636.

HaRRIS, H. 1962. Biochemical Genetics. Cambridge, Cambridge Univ. Press, $554 \mathrm{p}$.

LERNER, A.B. \& T.B. FITZPATRICK. 1950. Biochemistry of Melanin Formation. Physiol. Rev. 30: 91-126.

MAYS, L.L. 1981. Genetics: a Molecular Approach. New York, MacMillan Publ. Co., 639p.

Sick, H. 1984. Ornitologia Brasileira. Brasília, Ed. Universidade de Brasília, vol. 1, 629p.

Silva, F. \& C.E. CAYe. 1992. Lista de Aves: Rio Grande do Sul. Porto Alegre, Divulgação Museu Ciências Pontifícia Universidade Católica do Rio Grande do Sul, 26p.

Veiga, L.A. \& E. Pardo. 1990. Ocorrência de um Caso de Albinismo em Sabiá Laranjeira. Arq. Biol. Tecnol. 33: 329-333.

VeigA, L.A.; A.T. Oliveira \& N.A. Gastal. 1995. Aves da Estação Ecológica 
do Taím. Arq. Biol. Tecnol. 38: 669-678.

WALTER, H.E. 1938. Genetics: an introduction of the study of heredity. New York, MacMillan Publ. Co., 442p.

Recebido em 30.VI.1995; aceito em 25.IX.1995. 